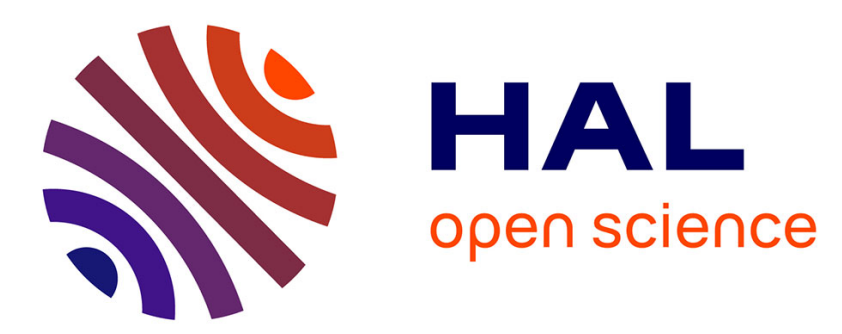

\title{
Physical Activity Among Older Adults: A Meta-review of EU-Funded Research Projects
}

\author{
Paula Alexandra Silva
}

\section{To cite this version:}

Paula Alexandra Silva. Physical Activity Among Older Adults: A Meta-review of EU-Funded Research Projects. 17th International Conference on Entertainment Computing (ICEC), Sep 2018, Poznan, Poland. pp.374-387, 10.1007/978-3-319-99426-0_47 . hal-02128608

\section{HAL Id: hal-02128608 https://hal.inria.fr/hal-02128608}

Submitted on 14 May 2019

HAL is a multi-disciplinary open access archive for the deposit and dissemination of scientific research documents, whether they are published or not. The documents may come from teaching and research institutions in France or abroad, or from public or private research centers.
L'archive ouverte pluridisciplinaire HAL, est destinée au dépôt et à la diffusion de documents scientifiques de niveau recherche, publiés ou non, émanant des établissements d'enseignement et de recherche français ou étrangers, des laboratoires publics ou privés. 


\title{
Physical Activity Among Older Adults: A Meta-Review of EU-Funded Research Projects
}

\author{
Paula Alexandra Silva \\ DigiMedia Research Center, University of Aveiro, Aveiro, Portugal \\ palexa@gmail.com
}

\begin{abstract}
To keep physically active is key to live a long and healthy life. It is therefore important to invest in research targeting the uptake of physical activity by the ageing population. This paper presents an overview of concluded EUfunded research projects which address the subject of physical activity among older adults. From an initial set of 330 projects, 29 are analyzed in this metareview that describes the projects, its goals, types of physical activity promoted, and technologies used. Entertainment technologies, in particular exergames, emerge as a frequent approach.
\end{abstract}

Keywords: Older Adults, Physical Activity, Entertainment, Active Ageing, AAL, CORDIS.

\section{Introduction}

Since the 1960's that global average life expectancy had not had such a fast increase as it did between 2000 and 2016 and, after an increased by 5.5 years, global life expectancy at birth in 2016 was 72.0 years [1]. While the evidence of people living longer marks a significant achievement for humankind, it also poses societies with the challenge of supporting citizens to live a healthier life, if they are to experience both a longer and satisfying extended life spam. Partaking in physical activity and/or exercise training programs can reduce the impacts of aging and contribute to improvements in health and well-being [2], [3]. The importance and benefits of engaging in physical activity for health promotion are numerous and range from improvements in depression [4] to preventing or slowing down disablement due to chronic diseases [5].

International organizations have been working with researchers, governments, and decision makers to ensure that physical activity becomes an important component of the daily life of each citizen. The World Health Organization (WHO) offers global recommendations on physical activity for health [6], where different levels of physical activity are recommended for different age groups. The specific guidelines for people aged $65+$ recommend aerobic physical activity, muscle strengthening activities, as well as balance training activities [7]. In particular, per week, older adults should engage in 150 minutes of moderate-intensity aerobic physical activity or in at least 75 minutes of vigorous-intensity aerobic physical activity (or equivalent combinations). Aerobic physical activity should be complemented with muscle- 
strengthening activities, involving major muscle groups, two or more days a week. In addition, it is suggested that older adults engage in physical activity that promotes balance three or more days per week, with this recommendation particularly applying to older adults with poor mobility. Recognizing the limitations imposed by specific health conditions, the WHO underlines that, if under limiting circumstances, older adults should be as physically active as their abilities and conditions allow.

All Europe Union (EU) member states are advised to implement the WHO guidance documents [8]. However, not all EU member states follow those recommendations, with some using instead similar guidelines from the United States Centers for Disease Control and Prevention, or from the Canadian Society for Exercise Physiology, and the American College of Sports Medicine [9].

During the last decade, aging has been part of the priorities in the agenda of the European Commission, with several initiatives targeting active aging and healthy aging. Several research projects have been funded addressing the ageing challenge. This paper presents a review and comparison of projects concerning physical activity and older adults, aiming to understand how the EU has been prioritizing the area and how projects have been addressing the subject. Two main sources of information are used to retrieve relevant projects: i) The Community Research and Development Information Service (CORDIS) database [5], the primary public repository and portal to disseminate information on all EU-funded research projects, and ii) The Active and Assistive Living (AAL) Programme Website [6], a funding activity which specifically targets the improvement of life conditions of older adults.

\section{Method}

The goal of this research was to identify completed EU-funded collaborative research projects, which had encouraged the uptake of physical activity among older adults and aimed at promoting health and well-being, to then determine the characteristics and investigate the approaches taken by such projects to achieve their goals. Besides understanding the extent of the EU efforts in this area, this research wanted to understand if physical activity was an important goal in those projects and if/what specific technologies were being utilized to support physical activity.

In order to identify EU-funded collaborative research projects, this study reviewed two online resources: the CORDIS database [10] and the AAL Website [11]. To determine relevant projects to include in this meta-review, i.e.: projects targeting the uptake of physical activity among older adults with a view promote their health and well-being, inclusion and exclusion criteria were defined. Projects targeting older adults, involving some sort of exercise and/or physical activity, aiming at health and well-being, and which had been concluded would be included. Projects involving only one single European country, or focusing solely on health monitoring aspects, biology studies, or on developing aids (e.g. walking aids) would be excluded.

Building upon these resources and criteria, this research then followed a number of steps (see Fig. 1 for an overview). First, it was necessary to retrieve all potentially 
interesting projects from the CORDIS database, for which five search strings ${ }^{1}$ were used. All projects funded by the AAL programme were deemed interesting, thus no specific search was needed to retrieve relevant projects from this source. Once a pool of projects was created, each project was screened, initially based on its title and short description, and then again, considering the full descriptions available online. In cases where information was insufficient to determine the relevance of the project, a quick search through the project website (if available) was made. Finally, projects, which remained in the data set, were analyzed with a view to addressing the research questions.

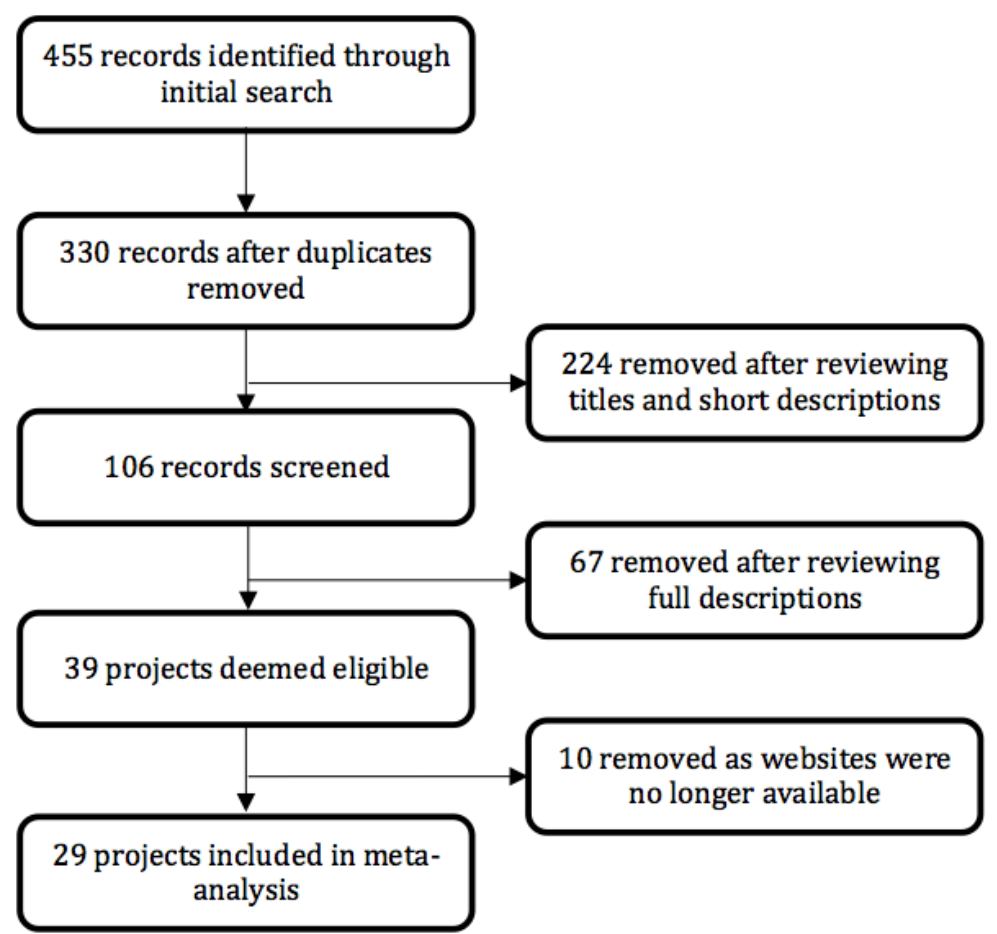

Fig. 1. Overview of the process followed to retrieve relevant projects.

\footnotetext{
${ }^{1}$ Five searches made: 'active' AND 'ageing' AND 'physical' AND 'health' AND 'activity' AND contenttype='project'; 'senior' AND 'exercise' AND contenttype='project'; 'ageing' AND 'health' AND 'exercise' AND contenttype='project'; 'active' AND 'ageing' AND 'exercise' AND contenttype='project'; 'old' AND 'exercise' AND contenttype='project'.
} 


\section{$3 \quad$ Results and Analysis}

The initial set of results included 455 records: 170 consisting of all concluded projects listed in the AAL website and 285 retrieved from the CORDIS database. Once repeated records were removed, 160 individual projects remained from the CORDIS database, which resulted in a pool of 330 eligible projects. After reviewing the project's titles and short descriptions, 106 projects remained in the dataset and were further analyzed based on their full descriptions and, whenever needed, also based on their websites. 67 results were excluded at this stage, two of them because they referred to Strategic Research Agendas, and the remaining because they did not meet the inclusion criteria. An extra ten projects were removed because their websites were no longer available and the information displayed in the CORDIS and AAL websites was rendered insufficient to make a proper assessment of the project's approach and activities. Figure 1 presents an overview of the process followed to retrieve the 29 projects identified as relevant and that from the basis for this research. The table in Appendix 1 shortly describes the 29 projects included in this meta-review.

\subsection{Characteristics of the Projects Included in the Meta-Review}

The 29 projects analyzed represent $€ 101$ millions of investment, from which $€ 65$ millions came from public/EU contribution. Nine different funding programs have funded these projects: seven by FP7-ICT, five by AAL-Call4, three by AAL-Call1, three by AAL-Call2, three by AAL-Call5, three by AAL-Call6, two by FP7-Health, two by $\mathrm{CIP}$, and one by H2020-EU.3.1. On average each of those projects lasted for 35.17 months (Max. 42, Min. 24) and cost an average of $€ 3.5$ millions (Max. $€ 7.4$ millions, Min $€ 1.4$ millions), with and average of $€ 2.2$ millions (Max. $€ 5.7$ millions, Min. $€ 33.7$ thousands) of public contribution. Those projects were more often coordinated by Germany (seven projects), followed by Spain (four projects), the Netherlands (four projects), France (three projects), Italy (three projects), and Switzerland (two projects). Countries such as Austria, Finland, Poland, Denmark, Greece, and Israel coordinated one project each. The remaining countries involved were diverse, often including the participation of more than one partner from the same country. The size of the consortia was also diverse involving on average 8.3 partners (Max. 14, Min. 5).

\subsection{Goals, Approaches, and Strategies Projects}

All 29 projects included in this meta-review foster the uptake of physical activity among older adults to some extent. The tables 1 in Appendix 2 captures the most important aspects analyzed in each of the projects included for review, such as: the goals, types of physical activities, and approaches followed by the projects, namely in terms of technology us and evidence of entertainment-related attributes. These aspects are detailed in the following subsections.

Main Goals of Projects. Into what concerns to the main goal of the projects, from the 29 projects analyzed, 25 have physical activity and/or its promotion as its main goal. However, five of these projects have parallel goals, such as: providing die- 
tary/nutrition advice, promoting cognitive training, and promoting stress management at work. For the remaining four projects, physical activity was a side goal. Projects claimed broader health improvements, from physical to cognitive and social, with most projects aiming to improve more than one of these areas. While nine projects had physical health in the outlook, seven aimed at physical and social health, six at physical and cognitive health, and another seven aimed to improve all three areas. Another aspect investigated was whether the projects were aiming at specific health conditions, for which the analysis concluded that most projects (19) did not aim at any specific condition. The remaining projects were looking into fall prevention (four projects), stress (two projects), chronic conditions, stroke, rehabilitation, loneliness and also malnutrition and cognitive decline.

Type of Physical Activity Encouraged by Projects. When it comes to the type of physical activity promoted, the majority of the projects (20) provided no specific details about the kind of physical activity targeted. The remaining nine projects resorted to different types of activities, with two projects resorting to all three main types of activities listed in the WHO recommendations, as described in section 1 . The exercises included ranged from simple chair-based exercises and walking to biking, hiking, gardening and the use of treadmills.

Nature of Technology Used. When analyzing the projects concerning the nature of the solutions they propose to address their goals, it is noteworthy that a significant number (19 out of 29) of the projects resorts to digital technology to achieve their objectives and that those same projects employ some sort of entertainment technology to do so $^{2}$. The most popular approach, employed by 12 projects, is to use games, namely exergames and serious games, to motivate to exercise. Another tendency, although less prevalent, is the use of virtual coaches which is observed in six projects. Several projects offer the possibility of defining personalized programs and of facilitating the exercise to take place in the home of the older person. Yet another commonality among projects is the monitoring of both physical activity and health conditions, as well as the use of both sensor technology and approaches to behavior change.

\section{Discussion and Concluding Remarks}

The analysis of the projects included in this meta-review shows that entertainment technologies, in particular games in the form of serious games and exergames, are indeed a popular approach, among EU-funded collaborative research projects, to addressing physical activity among older adults. From the 29 projects analyzed, 19 use some sort of entertainment technology to achieve their goals. It is important to note that this study looked only at projects, which have already been concluded. Given the

\footnotetext{
${ }^{2}$ Appendix 2 presents an overview of the projects included in this meta-review, where the projects that clearly resort to entertainment technologies are indicated in Bold Underline; projects in which this connection is not so clear are indicated in Underline, and projects where this link is not apparent are in plain text. The same tables also display information regarding the goals, types of physical activities, and approaches followed by the projects
} 
rising interest in games, serious games, exergames, and gamification in recent years, it is likely that the number of projects using technology and entertainment would be even higher in the near future, when ongoing projects would have been completed and thus included in the research.

To correctly interpret the results presented in this study it is important to highlight that conclusion were solely drawn upon the analysis of information which is publicly available online, therefore interpretations are based on incomplete descriptions. To this adds the fact that a single researcher performed the research and some level of subjectivity should be expected. Furthermore, projects were retrieved from only two sources, so an additional more exhaustive search and inclusive study warrants further investigation and fully fledged conclusions and findings. In the future, it would be interesting to extend the research to the study of the specific characteristics of the entertainment approaches employed and the understanding of the most effective ones.

\section{References}

[1] "WHO | Life expectancy," WHO. [Online]. Available: http://www.who.int/gho/mortality_burden_disease/life_tables/situation_trends_text/en/. [Accessed: 07-Jul-2018].

[2] E. Ciolac, "Exercise training as a preventive tool for age-related disorders: a brief review," Clinics, vol. 68, no. 5, pp. 710-717, May 2013.

[3] W. J. Chodzko-Zajko et al., "Exercise and Physical Activity for Older Adults:," Med. Sci. Sports Exerc., vol. 41, no. 7, pp. 1510-1530, Jul. 2009.

[4] H. Silveira, H. Moraes, N. Oliveira, E. S. F. Coutinho, J. Laks, and A. Deslandes, "Physical Exercise and Clinically Depressed Patients: A Systematic Review and Meta-Analysis," Neuropsychobiology, vol. 67, no. 2, pp. 61-68, 2013.

[5] E. Tak, R. Kuiper, A. Chorus, and M. Hopman-Rock, "Prevention of onset and progression of basic ADL disability by physical activity in community dwelling older adults: A meta-analysis," Ageing Res. Rev., vol. 12, no. 1, pp. 329-338, Jan. 2013.

[6] "WHO | Global recommendations on physical activity for health," WHO. [Online]. Available: http://www.who.int/dietphysicalactivity/factsheet_recommendations/en/. [Accessed: 05-Jul-2018].

[7] "WHO | Physical Activity and Older Adults," WHO. [Online]. Available: http://www.who.int/dietphysicalactivity/factsheet_olderadults/en/. [Accessed: 10-Apr2016].

[8] EU Working Group "Sport and Health," "EU Physical Activity Guidelines: Recommended Policy Actions in Support of Health-Enhancing Physical Activity.” 2008.

[9] WHO Regional Office for Europe, "Factsheets on Health-enhancing Physical Activity in the 28 European Union Member States of the WHO European Region,” 2015. [Online]. Available: http://ec.europa.eu/sport/library/factsheets/eu-wide-overview-methods.pdf. [Accessed: 11-Apr-2016].

[10] "CORDIS | European Commission." [Online]. Available: https://cordis.europa.eu/home_en.html. [Accessed: 05-Jul-2018].

[11] “ACTIVE AND ASSISTED LIVING PROGRAMME | ICT for ageing well.” [Online]. Available: http://www.aal-europe.eu/. [Accessed: 05-Jul-2018]. 


\section{Appendix 1: Project Descriptions}

\begin{tabular}{|c|c|}
\hline Acronym & Project Description \\
\hline GameUP & $\begin{array}{l}\text { Sustain mobility of older adults through exergames that include exercises } \\
\text { defined by physiotherapists. The system developed by the project has a } \\
\text { coach who advises and sets goals for the older person. }\end{array}$ \\
\hline$\underline{\mathrm{AIB}}$ & $\begin{array}{l}\text { Create a process and technologies to covering the full chain of fall risk man- } \\
\text { agement, from assessment, to preventive recommendations, care plan, and } \\
\text { interventions for fall prevention. }\end{array}$ \\
\hline FARSEEING & $\begin{array}{l}\text { Develop and test a falls management service (for prevention and prediction), } \\
\text { together with assessment of exergames to improve strength and balance, } \\
\text { thus reducing risk of falls. }\end{array}$ \\
\hline IS-ACTIVE & $\begin{array}{l}\text { To devise a person-centric healthcare solution for older adults with chronic } \\
\text { conditions based on miniaturized wireless inertial sensors, which provide } \\
\text { distributed motion capture and intelligent recognition of activities. }\end{array}$ \\
\hline A2E2 & $\begin{array}{l}\mathrm{A}^{2} \mathrm{E}^{2} \text { aims at breaking sedentary life styles though ambient virtual coaching } \\
\text { motivating elderly before, during and after daily activities. } \mathrm{A}^{2} \mathrm{E}^{2} \text { allows for } \\
\text { systematic interaction and adaptive feedback and selection of tasks. }\end{array}$ \\
\hline Join-In & $\begin{array}{l}\text { Develop a social networking platform for elderly citizens to encourage and } \\
\text { support communication and socializing. Solution includes computer game to } \\
\text { enhance cognitive abilities, biking exergames, and other video exercises. }\end{array}$ \\
\hline V2me & $\begin{array}{l}\text { Increase integration of older people in the society through the provision of } \\
\text { advanced social connectedness and social network services and activities. }\end{array}$ \\
\hline iStoppFalls & $\begin{array}{l}\text { Develop technologies which can be integrated in daily life practices of older } \\
\text { people living at home, and allow for continuous exercise training, reliable } \\
\text { fall risk assessment, and appropriate feed-back mechanisms. }\end{array}$ \\
\hline $\begin{array}{l}\text { Long-Lasting } \\
\text { Memories }\end{array}$ & $\begin{array}{l}\text { The LLM platform that targets mind, body and fitness through three compo- } \\
\text { nents: the Physical Training, the Cognitive Training and the Independent } \\
\text { Living Component. }\end{array}$ \\
\hline MOB & $\begin{array}{l}\text { Motivate older adults to increase physical activity and exercise cognitive } \\
\text { skills through an at-home system based on gaming environment that pro- } \\
\text { vides a truly innovative and enjoyable approach to healthy living and ageing. }\end{array}$ \\
\hline PAMAP & $\begin{array}{l}\text { PAMAP helps patients at home to perform their rehabilitation exercises by } \\
\text { monitoring and providing feedback to patients and their caregivers about } \\
\text { level of activity. }\end{array}$ \\
\hline Rehab@Home & $\begin{array}{l}\text { Rehabilitation after stroke at home with serious games in order to create the } \\
\text { necessary motivation to continue at home rehabilitation after stroke. }\end{array}$ \\
\hline SAFEMOVE & $\begin{array}{l}\text { The project aims to increase the mobility of the elderly, both at home and on } \\
\text { journeys, through encouraging self-confidence in own abilities. }\end{array}$ \\
\hline V-TIME & $\begin{array}{l}\text { V-TIME proposes a unique rehabilitation-like training program that simulta- } \\
\text { neously targets multiple elements of fall risk and teaches individuals new } \\
\text { strategies for fall prevention and maintenance of a healthy lifestyle in a safe } \\
\text { and enjoyable manner. }\end{array}$ \\
\hline DOREMI & $\begin{array}{l}\text { To develop a solution for older people to prolong their functional and cogni- } \\
\text { tive capacity by empowering, stimulating and unobtrusively monitoring their } \\
\text { daily activities; these are monitored by professionals. }\end{array}$ \\
\hline BeatHealth & $\begin{array}{l}\text { Exploit the link between music and movement for boosting individual per- } \\
\text { formance and enhancing health and wellness. }\end{array}$ \\
\hline Inspiration & $\begin{array}{l}\text { Help older adults live a healthier life and to stay mentally and physically fit. } \\
\text { Besides a digital coach, system provides health tips and a daily planner. } \\
\text { Recorded activities can be accessed by relatives, friends and caregivers. }\end{array}$ \\
\hline
\end{tabular}




\begin{tabular}{|c|c|}
\hline Acronym & Project Description \\
\hline PERSSILAA & $\begin{array}{l}\text { Innovates the way care services are organized. From fragmented, reactive } \\
\text { disease management into preventive, personalized services that are offered } \\
\text { through local community services and telemedicine technology. }\end{array}$ \\
\hline Wellbeing & $\begin{array}{l}\text { Wellbeing offers a holistic platform, combining physical exercises, work- } \\
\text { place ergonomics, nutritional balance, and stress management in order to } \\
\text { ensure a healthy life at the workplace. }\end{array}$ \\
\hline$\underline{\text { TRAINUTRI }}$ & $\begin{array}{l}\text { To raise consciousness about self wellness, by developing healthy habits and } \\
\text { enabling exchange of knowledge on physical and nutritional healthy habits. }\end{array}$ \\
\hline$\underline{\mathrm{ACANTO}}$ & $\begin{array}{l}\text { To spur older adults into a sustainable and regular level of physical exercise } \\
\text { under the guidance and the supervision of their carers. }\end{array}$ \\
\hline MOTION & $\begin{array}{l}\text { Develop an ICT-based service for remote multi-user physical training of } \\
\text { seniors at home by specialized coaches. }\end{array}$ \\
\hline Fit4Work & $\begin{array}{l}\text { A system for self-management (detecting, monitoring and countering) of } \\
\text { physical and mental fitness of older workers. }\end{array}$ \\
\hline ELF@,Home & $\begin{array}{l}\text { Elderly self-care based on self-check of health conditions and self-fitness at } \\
\text { home ( personal trainer at home). }\end{array}$ \\
\hline Alfred & $\begin{array}{l}\text { Develop a mobile, personalized assistant for the elderly, which helps them } \\
\text { stay independent, coordinate with carers and foster their social contacts. }\end{array}$ \\
\hline $\begin{array}{l}\text { PhysioDom- } \\
\text { HDIM }\end{array}$ & $\begin{array}{l}\text { To guide elder people in their health well-being and independence, provid- } \\
\text { ing physical activity and dietary coaching in their own home. }\end{array}$ \\
\hline Florence & $\begin{array}{l}\text { Improve the well-being of elderly (and their caregivers) and efficiency in } \\
\text { care through AAL services supported by a general-purpose robot platform. }\end{array}$ \\
\hline DOSSY & $\begin{array}{l}\text { Develop an intelligent outdoors navigation app with high quality route in- } \\
\text { formation and basic safety system. }\end{array}$ \\
\hline Give\&Take & $\begin{array}{l}\text { Strengthen the quality of life of senior citizens through occupation and so- } \\
\text { cial engagement as a key to mental, social and physical fitness. Also, sup- } \\
\text { port civic engagement and ability to live independently. }\end{array}$ \\
\hline \multicolumn{2}{|c|}{$\begin{array}{l}\text { Note: The use of entertainment is clear for the project in bold underline, unclear for the projects } \\
\text { in bold, and not used by the remaining projects. }\end{array}$} \\
\hline
\end{tabular}


Appendix 2: Projects Characteristics

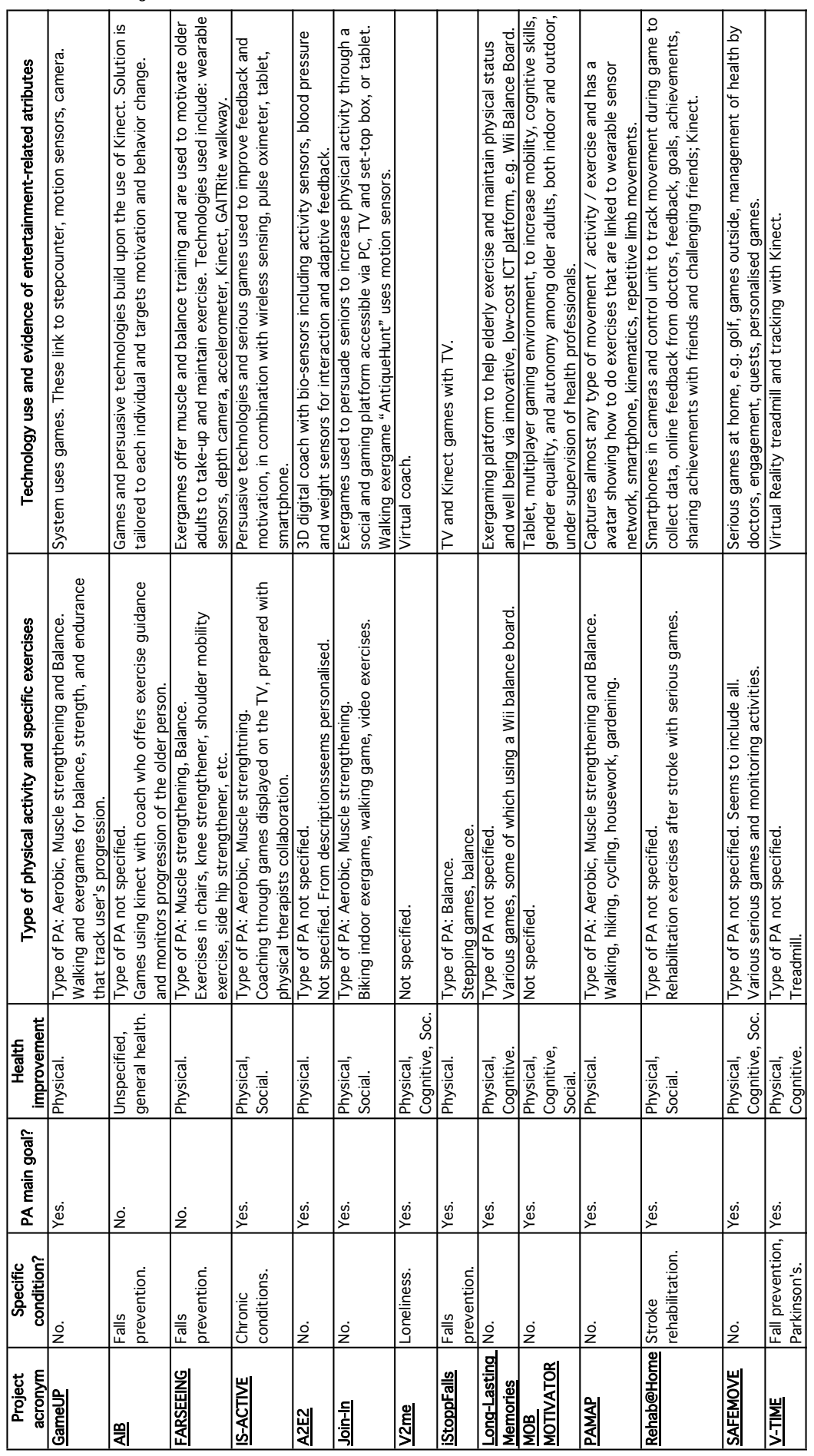




\begin{tabular}{|c|c|c|c|c|c|c|c|c|c|c|c|c|c|c|c|c|}
\hline 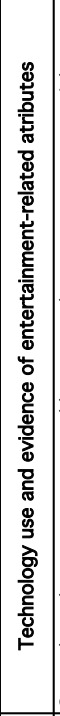 & 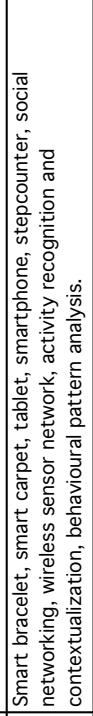 & 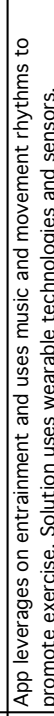 & 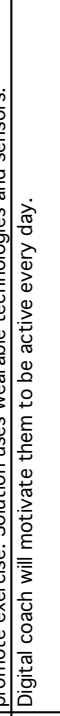 & 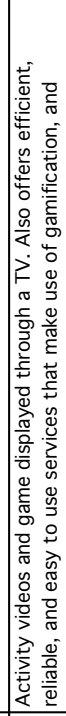 & 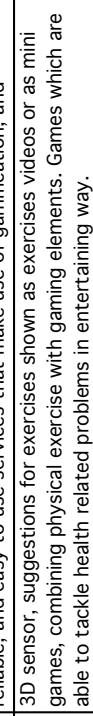 & 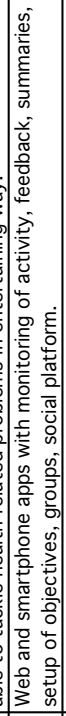 & 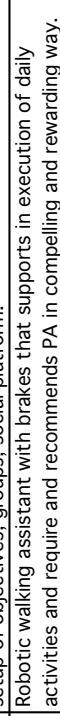 & 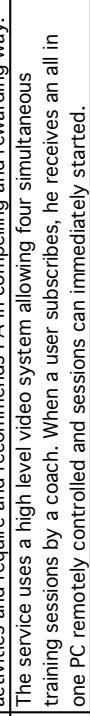 & 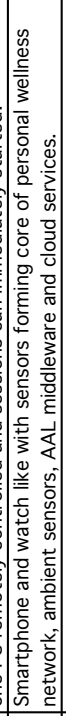 & 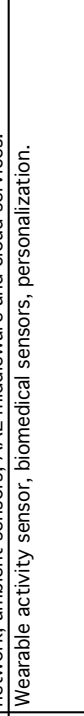 & 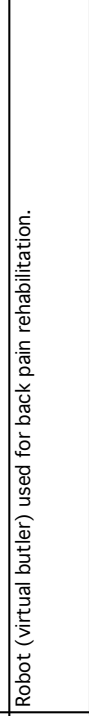 & 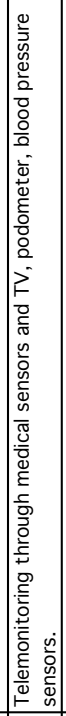 & 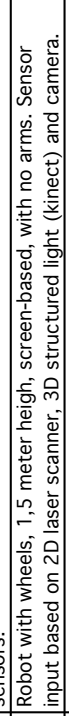 & 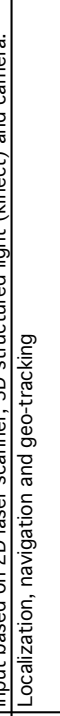 & 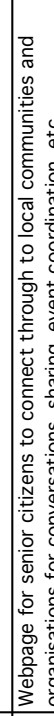 & 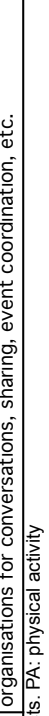 \\
\hline 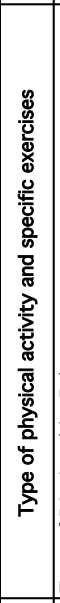 & 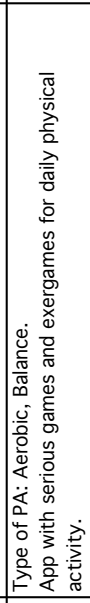 & 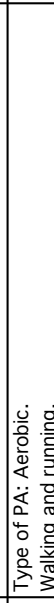 & 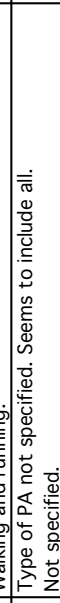 & & 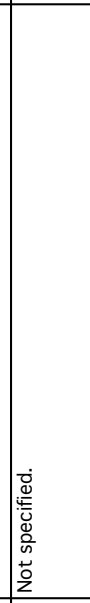 & 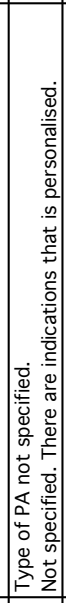 & 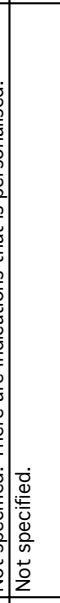 & 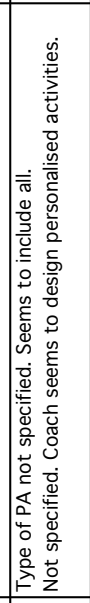 & 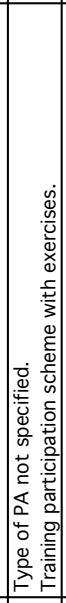 & 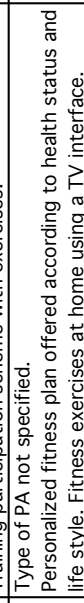 & 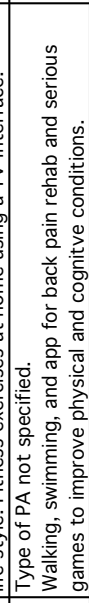 & 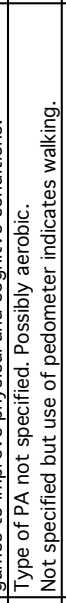 & 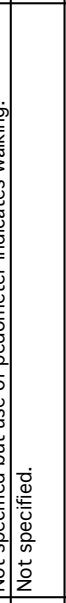 & 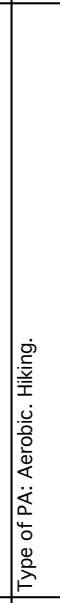 & 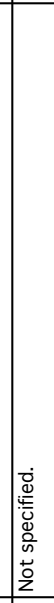 & 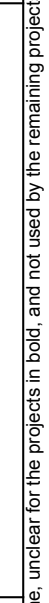 \\
\hline 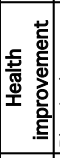 & 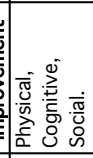 & 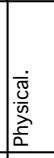 & 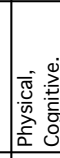 & 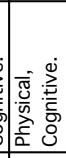 & 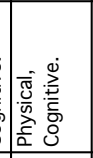 & 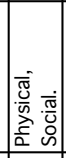 & b. & 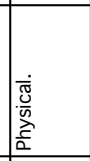 & 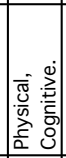 & 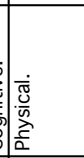 & 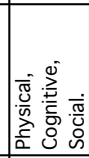 & 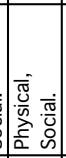 & 离 & & & 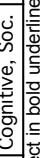 \\
\hline 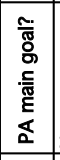 & 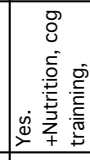 & $\dot{\infty}$ & 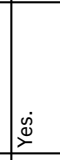 & 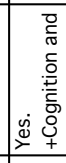 & 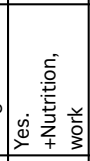 & $\stackrel{\infty}{\infty}$ & $\mid \dot{\Delta}$ & 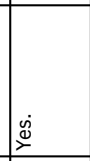 & 岕 & 岕 & $\dot{q}$ & 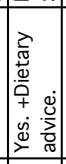 & $\begin{array}{l}0 \\
0\end{array}$ & & $\dot{z}$ & 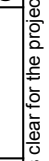 \\
\hline . & 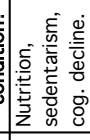 & i & ż & ż & 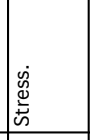 & í & í & ì & 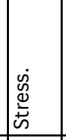 & $\frac{\dot{2}}{2}$ & $\frac{8}{2}$ & $\frac{\dot{q}}{2}$ & $\frac{8}{2}$ & $\frac{8}{2}$ & $\frac{8}{2}$ & 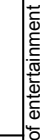 \\
\hline . & & 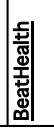 & $\mid$ & 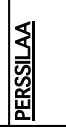 & 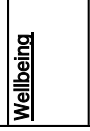 & 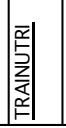 & $\left|\begin{array}{l}0 \\
\vdots \\
0 \\
\vdots \\
\mid\end{array}\right|$ & 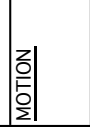 & | & 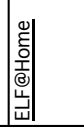 & वै & 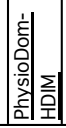 & 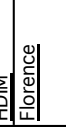 & 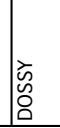 & $\mid$ & 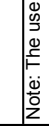 \\
\hline
\end{tabular}

